\title{
Epidemiology of Hepatitis C Virus and Human Immunodeficiency Virus Co- Infection and Challenges in Their Diagnosis
}

\author{
Parul Punia ${ }^{1}$, Anita Chakravarti ${ }^{1}$, Anjar Ashraf ${ }^{1}$, Preena Bhalla ${ }^{1}$, Richa Dewan ${ }^{2}$ \\ ${ }^{1}$ Department of Microbiology, Maulana Azad Medical College, New Delhi, India \\ ${ }^{2}$ Department of Medicine, Maulana Azad Medical College, New Delhi, India
}

\begin{abstract}
Objective: To screen HCV infection in HIV infected individuals and to compare the genotype and viral load of $\mathrm{HCV}$ in these co infected patients versus HIV negative individuals.

Methods: Serum samples from 70 HIV infected patients and 70 HIV negative individuals who enrolled in the ART center were retrospectively analyzed for the presence of anti HCV antibodies and for HCV RNA. Genotyping and viral load were further determined in HCV RNA positive patients.

Results: HCV infection (either positive for anti HCV Ab, or HCV RNA or both) was found in $8.57 \%$ HIV infected cases as compared to $2.85 \%$ individuals in the HIV uninfected control group. HCV RNA levels were higher in HIV infected subjects versus HIV negative individuals. Among the HIV positive cases, out of the three HCV RNA positive cases, two individuals had genotype 3 and one individual was found to have mixed genotype $(1+3)$ as compared to genotype 1 and genotype 3 in HIV negative healthy controls.
\end{abstract}

Conclusion: In our study, HCV infection was found more frequently in HIV infected individuals as compared to HIV non infected individuals. Therefore a routine screening test followed by a confirmatory test should be made mandatory in co infected patients. J Microbiol Infect Dis 2017; 7(4):167-172

Keywords: HIV, HCV, Genotype, Co-infection, Viral load

\section{INTRODUCTION}

Viral infections like hepatitis $\mathrm{C}$ virus (HCV) have been a problem in HIV positive patients because of the shared routes of transmission, thus continuing the incessant trepidations about effects of HIV. Global prevalence of HCV coinfection with HIV has been found to be $12-15 \%$, whereas amongst studies done in India have shown varied prevalence in different geographical areas ranging from $2-8 \%[1]$.

Clinically, Hepatitis C infection presents as a severe disease in HIV-infected individuals compared to infection with $\mathrm{HCV}$ alone with patients resorting to a faster progression of $\mathrm{HCV}$ related liver fibrosis along with more rapid headway to liver failure or hepatocellular carcinoma (HCC) $[2,3]$. It has been seen that patients who do not spontaneously get resolved with HCV infection have either not been able to develop CD4 T-cell responses or have been unable to sustain these responses resulting in subsequent relapse of HCV viremia [4].

The impacts of HIV on serological and molecular parameters of HCV are poorly characterized and co infected individuals more frequently present with atypical serology thus dithering the means of diagnosis. The effect of HCV on HIV progression is poorly understood and mostly the studies have shown no impact of HCV on HIV disease progression [2].

Furthermore, treatment is generally more complex in co infected patients as a result of myelo-suppression, drug interactions, antiretroviral related hepatotoxicity, and advanced HIV disease. Treatment responses have been better in HCV mono-infected cases as compared to co-infected cases.

Various guidelines have been formulated in the United States and Europe that recommend 
compulsory screening of all HIV infected individuals for infection with HCV to help in appropriate management of such patients. In developing countries like India, no such guidelines are available

All this has lent a sense of urgency for formulating a programmatic response to address this gigantic public health problem and thus this study has been undertaken to establish a correlation between $\mathrm{HIV}$ and HCV and to evaluate the severity of HCV in HIV infected individuals.

\section{METHODS}

The present study was conducted in Virology laboratory in the Department of Microbiology. It was a cross sectional study conducted on individuals in the age group 18-49 years attending the Integrated Counseling and Testing Center (ICTC). The cases consisted of 70 newly diagnosed ART naïve HIV infected individuals. The control group consisted of age-group and sex matched 70 HIV non infected high risk individuals. The high risk group included commercial sex workers, intravenous drug abusers, men who have sex with men, recipients of repeated blood transfusion and individuals with history of multiple sexual partners.

Blood samples $(5 \mathrm{ml})$ were collected from all these individuals after informed consent and proper counseling. Whole blood was collected in a sterile vacutainer containing K-3 EDTA (liquid) as an anticoagulant for absolute CD-4 Tlymphocyte count. Serum was separated and kept in aliquots at $-700 \mathrm{C}$ until tested for HIV and HCV using commercially available kits as per the manufacturer's instructions.

Serological diagnosis of HIV was done by three rapid tests to detect HIV-1 and HIV-2 antibodies as per strategy 3 of NACO guidelines which included: COMBAIDS - RS Advantage - ST (Span Diagnostics Ltd); Retrocheck HIV - WB (Qualpro Diagnostics) and HIV 1/2/0 Tri-line (Aco Biotech Co ltd).

Assessment of immunological status was done by determining the absolute CD-4 T lymphocyte count by FACSCountTM (Becton Dickinson). The HIV infected individuals were classified into three groups based on the CD-4 count and was staged clinically in accordance with the WHO guidelines [5].
For serodiagnosis of hepatitis $\mathrm{C}$ virus infection anti HCV Ab were detected using commercially available ELISA Kit- Hepalisa (J. Mitra \& Co, India). Extracted RNA was further subjected to reverse transcriptase-nested-polymerase chain reaction (RT-PCR) for 5' NCR- core region which is the conserved region of the $\mathrm{HCV}$ genome (Mellor et al 1995) for the detection of HCV RNA[6].The HCV RNA positive serum samples were employed to quantification to determine the viral load by the method of Martel et al 1999 using Taq Man Chemistry and genotyping was performed in these samples by Restriction fragment length polymorphism using the method of Chinchai et al $[7,8]$.

Statistical methods: SPSS-18 was used for statistical analysis. Chi-square test was used to compare proportions of two groups.

\section{RESULTS}

A total of 70 HIV positive patients were included in the study. We observed male gender predominance (44 males and 25 females) with only one transgender in the whole study group. Mean age group of the study population was 33.8 years. Heterosexual contact $(80 \%)$ was the predominant mode of acquiring HIV infection, followed by blood transfusion (17.1\%), intravenous drug use and needle prick equally common (4.3\%).

Among the 70 HIV infected cases, six (8.6\%) were found to be HIV/HCV co-infected (i.e. HIV positive individual either positive for anti HCV Ab, or HCV RNA or both) while among the HIV uninfected control group, only 2 out of $70(2.9 \%)$ individuals were found to be $\mathrm{HIV} / \mathrm{HCV}$ coinfected $(p=0.145)$. Amongst the HIV infected males, 5/ $44(11.4 \%)$ were reactive for $\mathrm{HCV}$ compared to $1 / 25(4.0 \%)$ of females $(p=0.549)$. Maximum prevalence of HCV-HIV co infection was found in the age group 20-30 years.

Out of the six HCV positive cases in HIV infected individuals, there were three cases positive only for HCV Ab, two were HCV RNA alone positive and only one sample was both HCV RNA and anti HCV Ab positive. Amongst these co infected cases CD-4 count below 350 cells/ul was observed in three individuals with one of them being only HCV Ab positive, second being only HCV RNA positive and the third with both $\mathrm{HCV} \mathrm{Ab}$ and $\mathrm{HCV}$ RNA positive as 
demonstrated in Table 1. HCV co-infection with HIV was seen in patients with only clinical

Table 1. Correlation of HCV positive cases with risk factors.

\begin{tabular}{lcc}
\hline Variables & $\begin{array}{c}\text { Total CD-4 } \\
\text { Count }\end{array}$ & Risk behavior \\
\hline Anti HCV-Ab alone & 720 & \\
positive (3 patients) & 138 & Heterosexual \\
& 550 & \\
HCV RNA alone positive & 304 & Heterosexual \\
(2 patients) & 437 & \\
Both positive (1 & & Heterosexual + \\
patient) & 122 & IVD \\
\hline IVD=Intravenous drug use & &
\end{tabular}

HCV viral load and genotyping was performed in all HCV RNA positive cases. Among the HIV positive individuals, it was observed that the patient with lowest CD-4 count had highest viral load. Also the viral load in HIV positive cases was higher in comparison to the HIV negative cases as shown in Table 2.

Among the HIV positive cases, out of the three HCV RNA positive cases, two individuals had genotype 3 and one individual was found to have mixed genotype $(1+3)$. Among the HIV negative healthy controls, one individual was detected with genotype 1 and the other with genotype 3. RFLP digestion pattern is shown in Figure 1. All the genotypes isolated in the study had heterosexual behavior as the risk factor associated with them. Only one case with mixed genotype $(1+3)$ gave history of heterosexual behavior as well as intravenous drug use. Highest viral load and lowest CD-4 count was found in the patient infected with mixed genotype as shown in the Figure 2.

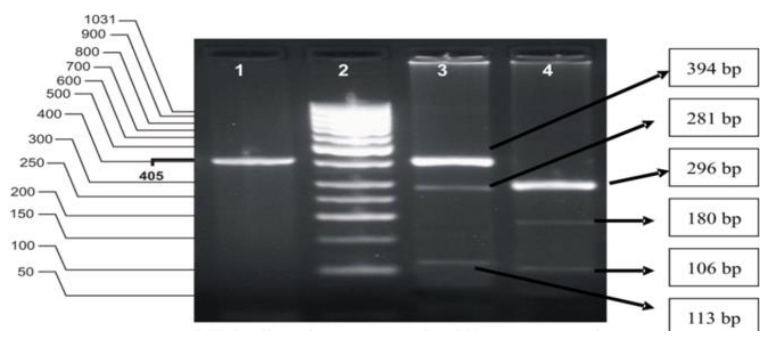

Figure 1. RFLP digestion pattern in $3 \%$ agarose gel: mixed genotype $3 a+3 b$.

Lane 1=Positive control (uncleaved PCR product $-405 \mathrm{bp}$ ); Lane 2=Molecular weight marker- 50 bp DNA ladder (1031, 900, 800, $700,600,500,400,300,250,200,150,100 \& 50$ bp); Lane $3=$ Accl digested pattern (394 and 8 bp for genotype $3 \mathrm{~b}$ and 281, 113 and 8 bp for genotype 3a); Lane 4= Mbol digested pattern (180 and 106 bp for genotype 3b \& 296 and 106 bp for genotype 3a) stages 2 and 3 . No HCV/HIV co-infection was observed in patients with clinical stages 1 and 4 .

Table 2. HCV viral load observed in the study groups.

\begin{tabular}{ll}
\hline Case identity No. & Viral load \\
\hline HIV positive Cases & \\
Case no 34 & $1.299 \times 103$ copies/ul \\
Case no 59 & $1.286 \times 103$ copies/ul \\
Case no 62 & $4.49 \times 102$ copies/ul \\
HIV negative Controls & \\
Case no 23 & $3.11 \times 102$ copies/ul \\
Case no 48 & $4.02 \times 102$ copies/ul \\
\hline
\end{tabular}

We also observed the various risk factors in these co infected patients and found that the risk behavior found predominantly in the co infected cases was heterosexual behavior (four cases).There was one case who gave a history of intravenous drug abuse (IVD) use and one case that had both heterosexual behavior and IVD use as risk factors. No association could be established between HCV infectivity and alcoholism. No statistical significance could be derived from raised aspartate transferases (AST) levels to HCV infectivity.

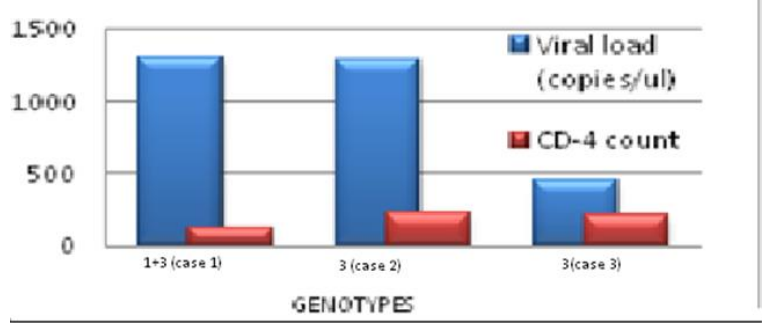

Figure 2. Correlation of HCV viral load with various HCV genotypes.

\section{DISCUSSION}

A prospective study on 70 HIV positive and 70 HIV negative individuals was conducted to know the prevalence of HCV. We included HIV negative high risk group as the control group so that the confounding factor of high risk behavior among HIV negative and HIV positive individuals could be removed and HIV itself as a risk factor for HCV acquisition could be studied. Subjects in our study had a mean age of 33.8 years (range 18-50 years) which is in accordance with the 
"HIV sentinel surveillance and HIV estimation in India 2007" report by NACO [9]. The percentage of male patients in our study was $62.9 \%(44 / 70)$ as compared with $35.7 \%(25 / 70)$ for female patients with only one transgender in the study group which again coincides with the aforementioned NACO report [9]. So our study population is quite representative of the national projection. In concordance with previous reports we also observed that the heterosexual contact is the commonest mode of transmission $(80.0 \%)$ followed by blood transfusion (17.1\%) for acquisition of HIV infection [10].

HCV prevalence in HIV subjects in our study was observed to be $8.6 \%$ (6 out of 70 ) which is higher than that previously reported in India which could possibly be due to the fact that we had further tested the sero-negative blood samples for HCV RNA thus diagnosing more number of patients [10]. Of the six HIV/HCV co infected subjects, there was one case positive for both anti-HCV antibody and HCV RNA, three cases positive for anti-HCV alone and two cases with isolated HCV RNA. HCV RNA positivity alone implies that these patients had active HCV infection but sero-conversion could not occur in them which could be due to the immunosuppressed state of these HIV positive patients, highlighting the importance of a confirmatory test like HCV RNA after initial screening with anti-HCV antibody and this has also been supported by other studies done outside India [11]. The reason for finding antibody alone and no RNA detection could be the spontaneous clearance of HCV infection in these subjects, again stressing upon the importance of above mentioned confirmatory tests.

Reason for the varying prevalence of coinfection in different studies may be the varying geographical areas and the modes of transmission. This is evident in a study in North East India where IVD is predominant mode of transmitting HIV, that a very high prevalence of $\mathrm{HIV/HCV} \mathrm{co} \mathrm{infection} \mathrm{was} \mathrm{reported} \mathrm{[12].}$

The frequency of HCV infection in HIV patients was also much higher in comparison to the HIV negative high risk group (2.85\%) simulating the findings of previous studies [10]. The prevalence of HCV infection in HIV negative individuals is $2.85 \%$ which is fairly high when compared to other studies that included a group of healthy individuals as controls indicating that high risk behavior is also an independent risk factor for HCV transmission [10].

A study similar to ours, in South India, observed that in the two cases in their study with only HCV RNA positive and no detectable antibodies, the CD-4 count was less than 350 cells/ul [13]. Whereas in our study, amongst the two cases with only HCV RNA positive, one had CD-4 count below 350 cells/ul and the other had CD-4 count above 350 cells/ul. The patient with CD-4 count $>350$ cells/ul may have been in the early stage of infection, and HCV antibodies usually take 6 weeks to 6 months to appear and the patient with CD-4 count $<350$ cells/ul might not have been able to develop an antibody response because of immunosuppression thus explaining the above findings. Also in our study we observed three cases with HCV antibody positive and no HCV RNA detection and one of them had CD-4 count below 350cells/ul. This patient might have spontaneously cleared the infection before immunosuppression occurred but remained anti $\mathrm{HCV}$ antibody positive thereafter.

The HCV RNA positive cases were further tested for viral load and genotyping. It has been reported previously also that HCV RNA levels remain much higher in co-infected subjects as compared to HIV negative individuals which is in concordance with our study.[14]. The above mentioned study has also reported a negative correlation between CD-4 count and HCV RNA levels similar to our study where out of the three HCV RNA positive cases, we observed highest viral load in the case with the lowest CD-4 count. By this we conclude that, there is poorer virologic control of $\mathrm{HCV}$ in HIV patients especially with low CD-4 count conferring an increased replicative ability to HCV.

In one such study done in South India, genotype 1 , in contrast to genotype 3 in our study, was found to be most common simulating the results of studies abroad $[15,16]$. In accordance with our study, a study done in Manipur, the predominant genotype was genotype $3 a$ followed by $1 b$ and then $3 b$ [17]. The reason for discordance in genotypes in various studies could be due to the epidemiological circumstances which exposed the individuals to 
varied genotypes in different geographical areas. For example in a study in North India, genotype 3 was the commonest genotype in HCV mono-infection followed by genotype 1 [18]. But to the best of our knowledge, no study has been done in North India on the genotype distribution in HIV-HCV co infected subjects.

In a study conducted in Europe, it was found that serum HCV RNA levels were higher in patients with genotype 1 [19]. In our study, we observed that the patient with mixed genotype infection had the highest viral load. None of the above studies had obtained infection with mixed genotype.

The patient with mixed HCV genotype (1 plus 3) infection in our study gave history of heterosexual behavior as well as intravenous drug abuse as risk factors, thus we conclude that repeated exposure to a large amount of virus and thus to many genotypes could have favored this mixed HCV genotype infection. This hypothesis could also explain the higher viral load observed in our study in mixed infection. In one such study abroad, the most common risk factor was determined to be intravenous drug use amongst genotype 1 [19].

We subjected the serum of all patients to various biochemical tests. We found that co infected patients with raised AST levels were more in number compared to patients who had AST levels in the normal range. Raised AST levels indicate a higher risk for hepatic complications in such patients [20].

Limitation of the study: Since the absolute number of samples giving RNA positivity in our study was very small therefore it is difficult to predict the trend of genotype distribution and risk behavior based on such small sample size. Moreover, we could not do liver biopsies which is a better means of assessing liver damage.

Thus we conclude that HIV infected individuals are at a higher risk of getting co-infected with $\mathrm{HCV}$ and false negative anti HCV antibody tests may be seen in HIV infected patients.. Since heterosexual risk behavior is the main risk factor involved in HCV infection in HIV, people should be educated and made aware of the risks involved and advised to use barrier protection. Lastly abnormality in liver function tests can be a useful guide to suspect HCV infection in HIV positive individuals.

In the end we would like to reiterate that although managing co infection seems a fiendish problem but simple measures like mandatory universal screening of all HIV infected patients for hepatitis $C$ using suitable confirmatory test wherever possible can bring a huge difference in the lives of these patients.

\section{ACKNOWLEDGMENTS}

Conflict of interest: The authors declare no personal or financial conflict of interest.

Funding disclosure: Non to declare

\section{REFERENCES}

1. Jain $M$, Chakravarti $A$, Verma V, Bhalla $P$. Seroprevalence of hepatitis viruses in patients infected with the human immunodeficiency virus. J Pathol Microbiol 2009; 52:17-19.

2. Brau N. Treatment of chronic hepatitis $C$ in human immunodeficiency virus/hepatitis $C$ viruscoinfected patients in the era of pegylated interferon and ribavirin. Semin Liver Dis 2005; 25:33-51.

3. Wright TL, Hollander $\mathrm{H}, \mathrm{Pu} \mathrm{X}$, et al. Hepatitis $\mathrm{C}$ in HIV-infected patients with and without AIDS: prevalence and relationship to patient survival. Hepatology 1994; 20:1152-1155.

4. Gerlach JT, Diepolder HM, Jung MC, et al. Recurrence of hepatitis $C$ virus after loss of virusspecific CD4 (+) T-cell response in acute hepatitis C. Gastroenterology 1999; 117:933-941.

5. Antiretroviral therapy for HIV infection in adults and adolescents: Recommendation for a public health approach. World Health Organization 2010 Revision cited 2010 January.

6. Mellor J, Holmes EC, Jarvis LM, Yap PL, Simmonds $P$. Investigation of the pattern of hepatitis $C$ virus sequence diversity in different geographical regions: implications for virus classification. The international HCV Collaborative Study group. J Gen Virol 1995; 76: 2493-2507.

7. Chinchai $T$, Labout $J$, Noppornpanth $S$, et al. Comparative study of different methods to genotype hepatitis $\mathrm{C}$ virus type 6 variants. J Virol Methods 2003; 109:195-201.

8. Yang JH, Lai JP, Douglas SD, Metzger D, Zhu $\mathrm{XH}, \mathrm{Ho}$ WZ. Real time RT- PCR for quantitation of hepatitis C virus RNA. J Virol Method 2002; 102:119-128. 
9. HIV Sentinel Surveillance and HIV estimation in India 2007: A Technical Brief. [Online]. 2008 [cited 2009 Apr 22]; Available from: URL: http://naco.gov.in/sites/default/files/HIV\%20Sentin el\%20Surveillance\%20and\%20HIV\%20Estimation \%202007_A\%20Technical\%20Brief.pdf

10. Gupta S, Singh S. Hepatitis B and C virus coinfections in human immunodeficiency virus positive north Indian patients. World J Gastroenterol 2006; 12:6879-6883.

11. George SL, Gebhardt J, Klinzman D, et al. Hepatitis C virus viremia in HIV infected individuals with negative HCV antibody tests. J Acquir Immun Defic Syndr 2002; 31:154-162.

12. Saha ML, Chakrabarty S, Panda S, et al. Prevalence of HIV and HBV infection amongst HIV seropositive intravenous drug users and heir noninjecting wives in Manipur, India. Indian $\mathrm{J}$ Med Res 2000; 111:37-39.

13. Saravanan S, Velu V, Kumarasamy N, et al. Coinfection of hepatitis $B$ and hepatitis $C$ virus in HIV infected patients in South India. World $J$ Gastroenterol 2007; 13; 5015-5020.

14. Matthews-Greer JM, Caldito GC, Adley SD, et al. Comparision of hepatitis $C$ viral loads in patients with or without Human Immunodeficiency Virus. Clin Diagn Lab Immun 2001; 8: 690-694.

15. Ponamgi S, Rahamathulla S, Kumar YN, et al. Prevalence of hepatitis C virus (HCV) coinfection in HIV infected individuals in South India and characterization of HCV genotypes. Indian $\mathrm{J}$ Med Microbiol 2009; 27:12-16.

16. Karchava M, Sharvadze L, Gatserelia L, Badridze $\mathrm{N}$, Tsertsvadze T. Prevaling HCV genotypes and subtypes among HIV infected patients in Georgia. Georgian Med News 2009; 177:51-55.

17. Pukhrambam PD, Singh NB, Singh LH, Devi KhS. Pattern of hepatitis C virus genotypes in HIV infected patients in RIMS, Hospital, Imphal, Manipur. J Commun Dis 2007; 39:21-24.

18. Chakravarti A, Dogra G, Verma V, Srivastava AP. Distribution patterns of HCV genotypes and its association with viral load. Indian J Med Research 2011; 133:326-331.

19. Soriano V, Mocroft A, Rockstorh J, et al. spontaneous viral clearance, viral load and genotype distribution of hepatitis $\mathrm{C}$ virus $(\mathrm{HCV})$ in HIV-infected patients with anti-HCV antibodies in Europe. JID 2008; 198:1337-1344.

20. Reuter S, Oette M, Wilhhelm FC, et al. Prevalence and characteristics of hepatitis $B$ and $C$ virus infections in treatment -naïve HIV-infected patients. Med Microbiol Immunol 2011; 200:39-49. 